\title{
Insulin pump therapy and continuous glucose monitoring in adults with type 2 diabetes: where are we now?
}

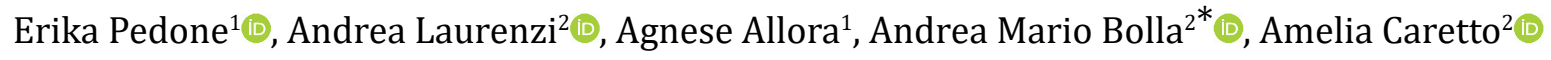 \\ ${ }^{1}$ Vita-Salute San Raffaele University, 20132 Milan, Italy \\ ${ }^{2}$ Department of Internal Medicine, IRCCS San Raffaele Scientific Institute, 20132 Milan, Italy
}

*Correspondence: Andrea Mario Bolla, Department of Internal Medicine, IRCCS San Raffaele Scientific Institute Via Olgettina 60, 20132 Milan, Italy. bolla.andreamario@gmail.com

Academic Editor: Alessandro Mantovani, University and Azienda Ospedaliera Universitaria Integrata, Italy

Received: August 10, 2020 Accepted: September 25, 2020 Published: October 30, 2020

Cite this article: Pedone E, Laurenzi A, Allora A, Bolla AM, Caretto A. Insulin pump therapy and continuous glucose monitoring in adults with type 2 diabetes: where are we now? Explor Med. 2020;1:314-30. https://doi.org/10.37349/emed.2020.00021

\begin{abstract}
Technology in diabetes is rapidly evolving, with the aim of helping affected people to safely optimize their blood glucose control. New technologies are now considered as an essential tool for managing glycemia predominantly in people with type 1 diabetes, and clinical trials have demonstrated that in these subjects the use of continuous subcutaneous insulin infusion (CSII) and continuous glucose monitoring (CGM) systems are associated with improved glycemic control along with a better quality of life. Literature regarding technologies and type 2 diabetes is relatively lacking, but innovations may have an important role also in the management of these patients. Some studies in adults with type 2 diabetes have shown benefits with the use of CGM in terms of glycemic variability and improved therapeutic adjustments. Clinical trials about CSII and CGM use in type 2 diabetes may have some pitfalls and future studies are needed to assess how these advanced systems could improve clinical outcomes and also ensure cost-effectiveness in this population. In this narrative review, we aim to highlight the most relevant studies on this topic and to focus on the potential role of new technological devices in type 2 diabetes management.
\end{abstract}

\section{Keywords}

Continuous glucose monitoring, continuous subcutaneous insulin infusion, cost-effectiveness, multiple daily injection, hypoglycemia, type 2 diabetes, diabetes technology

\section{Introduction}

When appropriate combination of oral antidiabetic agents and lifestyle changes fails to provide adequate glycemic control, people with type 2 diabetes (T2D) may require insulin treatment. Some studies have compared the use of insulin pump therapy in T2D to multiple daily injections (MDI), suggesting the possibility of stable and long-term improvements in glycated hemoglobin (HbA1c) with lower insulin requirement and overall acceptable safety profile [1]. As for type 1 diabetes (T1D), self-monitoring blood glucose (SMBG) appears to be an essential tool for daily management of therapy also in T2D. In fact, structured glucose monitoring,

(C) The Author(s) 2020. This is an Open Access article licensed under a Creative Commons Attribution 4.0 International License (https://creativecommons.org/licenses/by/4.0/), which permits unrestricted use, sharing, adaptation, distribution and reproduction in any medium or format, for any purpose, even commercially, as long as you give appropriate credit to the original author(s) and the source, provide a link to the Creative Commons license, and indicate if changes were made. 
within a good therapeutic adherence, has been associated with an improvement of glycemic control also in T2D [2]. On the other hand, there are limited evidences about the efficacy of continuous glucose monitoring (CGM) in reducing HbA1c compared to SMBG in insulin-treated T2D subjects [3]. Intermittently scanned CGM (isCGM), a CGM system without alerts for low or high glucose, was found to reduce hypoglycemic risk in subjects with well-controlled T1D, but only small studies are available in subjects with T2D on insulin therapy [4].

Overall outcomes of insulin-pump therapy and CGM in T2D are somehow controversial and still not well defined, and, as a consequence, their role in clinical practice is still debated, especially in terms of costeffectiveness. The aim of this review is to highlight the current evidence on the use of continuous subcutaneous insulin infusion (CSII) and CGM in T2D with or without previous insulin therapy, focusing on safety, reduction of hypoglycemic episodes, time spent in hyperglycemia, and cost-effectiveness.

\section{CSII and T2D}

People with T2D often require insulin therapy, especially as beta-cell function declines with the progression of the disease. Since 2009, the American Diabetes Association (ADA) and the European Association for the Study of Diabetes (EASD) Consensus Treatment Algorithm for T2D [5] recommended basal or intensive insulin therapy as steps of glucose lowering therapy. When insulin therapy is needed, T2D subjects, compared to T1D people, may require relatively larger doses of insulin ( $\geq 1 \mathrm{unit} / \mathrm{kg}$ ) in order to balance insulin resistance and reduce $\mathrm{HbA1c}$ to the target level. As known, insulin therapy is associated with the risk of hypoglycemia also in T2D, despite much less frequently than in T1D, with a rate of 1-3 per 100 patient-years of severe hypoglycemic episodes (in a setting of a mean HbA1c of about 7\%) [6]. Over one-third of people with T2D on MDI still do not achieve the ADA HbA1c goal of < 7\% [7], so given the increased amount of insulin often required in T2D and the long-term failure in glycemic control, CSII has been explored as an alternative to conventional or intensive insulin therapy.

Compared to MDI, insulin pump therapy faithfully mimics the physiological beta-cells secretion and allows to change insulin doses more accurately. Insulin pumps are filled with rapid-acting insulin analogues, and offer the advantage to infuse insulin at a continuous basal rate to control glucose during fasting, and to administer boluses to cover meals and to correct hyperglycemia. For these reasons, when used appropriately in T1D, insulin pump has shown benefits in terms of glycemic control improvement [8], reduction of glycemic variability [9], less frequent severe hypoglycemic events [10], lower insulin daily requirement [11], and improvement of quality of life (QoL) including a more flexible lifestyle [12]. The current generation of intelligent pumps includes specific features like bolus calculator, which allows to optimize prandial insulin dose, count of insulin on board (insulin still remaining active) to minimize hypoglycemic risk, and the possibility to connect with glucometers or CGM systems (sensor augmented pump, SAP). Moreover, the recent algorithms named "low glucose suspend" (LGS) and "predictive LGS" (PLGS) enable automatic suspension of insulin infusion when the sensor reveals an interstitial glucose value below a determined threshold or predicts imminent hypoglycemia. These kinds of devices are helpful especially for patients with an elevated hypoglycemic risk or with hypoglycemia unawareness. However, insulin pump efficacy is still highly dependent on the users and the experience of multidisciplinary diabetes team [12].

The most important clinical trials regarding CSII as an option in T2D treatment are summarized in Table 1. CSII therapy may be useful in subjects with T2D who require intensive insulin therapy, as an alternative to MDI, due to an inadequate glycemic control despite an optimized combination of oral antidiabetic drugs (OADs). Raskin et al. [1], in a multicenter, randomized, 24-week study, showed that CSII was preferred by at least $93 \%$ of pump-naive T2D patients, appropriately trained to use technology, because of its flexibility and easiness of use. Comparing the efficacy and safety of CSII with MDI therapy, a significant reduction of eightpoint blood-glucose (BG) values 90 min after breakfast $(P=0.019)$ was showed among CSII group, while HbA1c decreased similarly for both groups from baseline $(P=0.05)$. Regarding glycemic variability, hyperglycemia was commonly reported in MDI treatment arm (CSII 5\% vs. MDI 18\%), and hypoglycemic episodes were comparable for both groups. A review of previous studies published in 2010 by Bode et al. [13] suggested that 
evidence supporting greater effectiveness of CSII on glycemic control in T2D was still insufficient, in spite of the preference of CSII modality among patients because of the improvement of their QoL.

Table 1. Randomized clinical trials (RCTs) comparing CSII and MDI among people with T2D

\begin{tabular}{|c|c|c|c|c|c|c|c|c|}
\hline Reference & $\begin{array}{l}\text { Study } \\
\text { population }\end{array}$ & $\begin{array}{l}\text { Age, } \\
\text { years } \\
\text { (mean } \\
\pm \text { SD) }\end{array}$ & Therapy & $\begin{array}{l}\text { Study design } \\
\text { and follow- } \\
\text { up }\end{array}$ & $\begin{array}{l}\text { Primary } \\
\text { endpoint }\end{array}$ & $\begin{array}{l}\text { Primary } \\
\text { results in CSII } \\
\text { group }\end{array}$ & $\begin{array}{l}\text { Change in } \\
\text { HbA1c }\end{array}$ & $\begin{array}{l}\text { Hypoglycemic } \\
\text { events (safety) }\end{array}$ \\
\hline $\begin{array}{l}\text { Raskin P, } \\
2003 \text { [1] }\end{array}$ & 132 & $\begin{array}{l}55.1 \pm \\
10.2\end{array}$ & $\begin{array}{l}\text { CSII vs. } \\
\text { MDI } \pm \\
\text { OADs }\end{array}$ & $\begin{array}{l}\text { Parallel; } 24 \\
\text { weeks }\end{array}$ & $\begin{array}{l}\text { - HbA1c } \\
\text { - Eight-point } \\
\text { BG profile } \\
\text { - Treatment } \\
\text { satisfaction }\end{array}$ & $\begin{array}{l}\text { - Reduction of } \\
\text { BG at } 90 \text { ' post- } \\
\text { breakfast } \\
\text { - Improved } \\
\text { treatment } \\
\text { satisfaction } \\
\text { favoring CSII }\end{array}$ & $\begin{array}{l}-0.62 \% \pm \\
1.11 \% \text { vs. } \\
-0.46 \% \\
\pm 0.89 \% \\
\text { (control) NS }\end{array}$ & No difference \\
\hline $\begin{array}{l}\text { Reznik Y, } \\
2014 \text { [14] }\end{array}$ & 331 & $\begin{array}{l}55.5 \pm \\
9.7\end{array}$ & $\begin{array}{l}\text { CSIl vs. } \\
\text { MDI } \pm \\
\text { OADs }\end{array}$ & $\begin{array}{l}\text { Interventional } \\
\text { (study phase); } \\
6 \text { months }\end{array}$ & $\mathrm{HbA1c}$ & $\begin{array}{l}\text { - Reduction in } \\
\text { HbA1c } \\
\text { - Decrease } \\
\text { in 24-h mean } \\
\text { glucose } \\
\text { concentration } \\
\text { - Reduction } \\
\text { of time in } \\
\text { hyperglycemia }\end{array}$ & $\begin{array}{l}-1.1 \% \pm \\
1.2 \% \text { vs. } \\
-0.4 \% \pm 1.1 \% \\
\text { (control) }{ }^{*}\end{array}$ & No difference \\
\hline $\begin{array}{l}\text { Aronson } \\
R, 2016 \\
{[15]}\end{array}$ & 331 & $\begin{array}{l}55.5 \pm \\
9.7\end{array}$ & $\begin{array}{l}\text { CSIl vs. } \\
\text { MDI } \pm \\
\text { OADs }\end{array}$ & $\begin{array}{l}\text { Interventional } \\
\text { (continuation } \\
\text { phase); } 12 \\
\text { months }\end{array}$ & $\mathrm{HbA} 1 \mathrm{c}$ & $\begin{array}{l}\text { - Sustained } \\
\text { improvement of } \\
\text { HbA1c in CSII } \\
\text { group } \\
\text { - Further } \\
\text { reduction in } \\
\text { MDI group after } \\
\text { switching to } \\
\text { CSII }\end{array}$ & $\begin{array}{l}-1.1 \% \pm \\
1.2 \% \text { vs. } \\
-0.4 \% \pm 1.1 \% \\
\text { (control) }^{*}\end{array}$ & No difference \\
\hline $\begin{array}{l}\text { Berthe E, } \\
2007 \text { [18] }\end{array}$ & 17 & $\begin{array}{l}55.2 \pm \\
6.6\end{array}$ & $\begin{array}{l}\text { CSIl vs. } \\
\text { MDI }\end{array}$ & $\begin{array}{l}\text { Cross-over; } \\
24 \text { weeks }\end{array}$ & $\begin{array}{l}\text { - HbA1c } \\
\text { - Six-point } \\
\text { BG profile } \\
\text { - 24-hour } \\
\text { CGM } \\
\text { - Treatment } \\
\text { satisfaction }\end{array}$ & $\begin{array}{l}\text { - Reduction in } \\
\text { HbA1c } \\
- \text { Reduction } \\
\text { of BG } \\
-\quad \text { Increase of } \\
\text { TIR } \\
- \text { Fall of } \\
\text { hyperglycemic } \\
\text { excursions }\end{array}$ & $\begin{array}{l}-1.3 \% \text { vs. } \\
-0.4 \% \\
(\text { control })^{\star *}\end{array}$ & No difference \\
\hline
\end{tabular}

${ }^{*} P<0.01 ;{ }^{*} P<0.05$. NA: not applicable; NS: not significant; TIR: time in range

A milestone in this topic is the OpT2mise study, which evaluated the efficacy of CSII therapy in T2D [14]. In this trial, adults with T2D and a poor glycemic control, despite adequate basal and postprandial insulin therapy, were randomized to CSII or to continuing MDI. CSII therapy determined a significant reduction of HbA1c $(P<0.0001)$ after 6 months of treatment. It is important to underline that in this study patients at baseline had a median BMI (body mass index) of 33.5 in pump treated group and 33.2 in MDI group, thus reflecting the typical phenotype of T2D patients with obesity and consequent insulin resistance rather than insulin deficiency. Two years later, the follow-up of OpT2mise trial showed a persistent improvement of $\mathrm{HbA1c}$ with a reduction of insulin requirement after one year of treatment [15]. In a meta-analysis, Pickup et al. [16] analyzed 5 RCTs on subjects with T2D comparing MDI and CSII therapy, and demonstrated that CSII allowed to achieve a better glycemic control than MDI along with a reduction of insulin requirement of about $26 \%$ and without weight gain. Moreover, the efficacy of CSII therapy was greater in patients with higher basal HbA1c and a greater insulin total daily dose.

Approximately $30 \%$ of people with T2D may require insulin therapy during the course of disease $[17,18]$, sometimes also due to intercurrent diseases. Most people with T2D requiring insulin therapy are cared for 
by primary healthcare practitioners who have usually not much knowledge of CSII compared with trained diabetes team [13]. In addition, CSII technology may be difficult and a potential barrier for adults with T2D, often receiving the diagnosis in elder age [19]. Moreover, CSII technology has higher costs compared to MDI. In the USA, according to national health insurance programs (Medicare and Medicaid), in T2D population, CSII may be prescribed in these situations: fasting C-peptide level $\leq 110 \%$ (or $\leq 200 \%$ if renal insufficiency) of the lower normal limit of the laboratory's measurement method with a concurrently obtained fasting blood glucose $(\mathrm{FBG}) \leq 225 \mathrm{mg} / \mathrm{dL}, 6$ months of MDI therapy, an average of four or more SMBG measures per day for 2 months, and evidence of suboptimal glycemic control defined as an HbA1c $\geq 7.0 \%$, history of significant glycemic excursions, or history of severe hypoglycemia or hypoglycemic unawareness [20]. In order to be cost-effective, switching from MDI to CSII in T2D must provide improved health outcomes overcoming the increased cost of technology [13]. In T2D, advanced features of modern insulin pumps are often unneeded. In this view, over the past few years, a new model of insulin pumps has been developed [21]. These simplified devices $\left({\mathrm{V}-\mathrm{Go}^{\circledR}}^{\circledR}\right.$ by Valeritas and PAQ by $\left.\mathrm{CeQur}{ }^{\circledR}\right)$ are generally smaller than the other pumps, attached directly to the skin with a short cannula, and only composed of mechanical components that deliver a fixed insulin basal rate, boluses, or both [22]. They are low cost and are fully disposable [21]. The V-Go ${ }^{\circledR}$ is a mechanical patch pump addressed to T2D patients, who delivers a 2 units bolus pressing a lock release and a delivery button [22]. The maximum daily dose is $76 \mathrm{U}$ (basal $40 \mathrm{U}$, maximum bolus $36 \mathrm{U}$ ) and it is approved for both U100 lispro and U100 aspart insulins. The PAQ is a multiday device that can hold up to 330 units of U100 insulin and comes in models that provide basal rates of $16 \mathrm{U}, 20 \mathrm{U}, 24 \mathrm{U}, 32 \mathrm{U}, 40 \mathrm{U}, 50 \mathrm{U}$, or $60 \mathrm{U}$ constantly in 24 hours [23]. These patch pumps are mainly preferred by patients with T2D treated with basal-bolus therapy, since they are small, lightweight, directly connected to the skin without tubing, and relatively inexpensive. However, they have some disadvantages, firstly the limited number of fixed basal doses, and then the need to change pump model in order to change the basal rate. Moreover, they do not track the quantity of insulin delivered and cannot be temporarily removed.

According to previously published RCT data, in T2D CSII may improve glycemic control both on shortterm and long-term, reducing HbA1c without an increase of hypoglycemic episodes or insulin requirement. Moreover, diabetes technology satisfaction scores and QoL seem to improve with CSII use in adults with T2D well supported to self-management of insulin pump therapy [24].

Regarding CSII and CGM combined systems, this technological therapy was originally developed mainly for T1D, but they can also be useful in insulin-treated T2D, especially for basal-bolus therapy [25]. The discrepancy between people with type 1 and type 2 diabetes in the use of CSII plus CGM systems may derive from lower glucose variability, more regular lifestyle, and greater difficulty in management of technological devices for people with T2D. It should also be considered that most meta-analyses combine studies designed to assess the effects of different devices, with differences in accuracy, precision, and user-friendliness. In fact, an important evolution in CGM technology has occurred in the last decade $[25,26]$.

However, today, available data that allow to support clinical and therapeutic decisions and choose what kind of patients are more likely to benefit from CSII, CGM or FGM are still insufficient. In fact, large-scale, pragmatic trials of adequate duration are needed to better define possible recommendations. At the moment, the limited available evidence does not support a widespread use of these combined technologies in T2D, and every single case should be carefully evaluated.

\section{CGM and T2D}

In the last years, several data have shown that CGM brings a positive effect on top of SMBG in T1D patients in terms of glycemic control. A randomized trial in adults with T1D receiving MDI found that adding CGM was associated with a significant reduction in HbA1c, hypoglycemic events, time spent in hyperglycemia, and glucose variability [27]. Despite a greater prevalence of people with T2D and the frequent requirement of insulin treatment, there is less evidence about the advantages of CGM in this population [28]. Today, many CGM systems have become available both for subjects with T1D and T2D. By providing glucose values as often as every 5 minutes, low and high glucose alerts, and glucose trend information, CGM can guide 
therapeutic decisions better than SMBG. A real-time CGM (rtCGM) system consists of a small disposable sensor, a transmitter, and a receiver. Some devices can show glucose measurements on a dedicated application on a smartphone. The sensor is inserted by the patient, changed every 7-14 days depending on the device, and measures glucose concentration in the interstitial fluid [28]. The transmitter is linked to the sensor and wireless communicates glucose levels to the receiver or the smartphone. The system provides a graph of glucose trend and alerts the user when glucose concentrations exceed or fall below customized thresholds [28]. In an RCT [29] of adults with T2D using therapeutic regimens other than prandial insulin (i.e. diet, life habits, or combination of various anti-hyperglycemic therapies, including basal insulin) showed that 12 weeks of intermittent CGM use was associated with significantly improved glucose control compared with SMBG four times per day. Similar results were highlighted by Beck and the DIAMOND study group [30] through an RCT of adults with T2D in MDI, randomly assigned to CGM or usual care. A significant reduction of $\mathrm{HbA} 1 \mathrm{c}$ was achieved in $73 \%$ of participants of CGM group vs. $49 \%$ of controls, while no differences were found in hypoglycemic episodes rate, and severe hypoglycemia or diabetic ketoacidosis did not occur in either groups [30]. In all these studies, HbA1c reduction occurred without any treatment intensification or increased hypoglycemic episodes, suggesting that benefits of rtCGM in T2D may be explained also by behavior and lifestyle modification, even in non-insulin-treated T2D subjects [31]. rtCGM appears to be more beneficial in T2D adults with higher basal HbA1c levels [32]. Available studies, as shown in Table 2, suggest an HbA1c reduction of about $0.5-0.6 \%$ up to $0.82 \%$, due to CGM use in MDI treated T2D patients, with no increased hypoglycemic events [33]. The use of CGM allows, in fact, an improved detection of hypoglycemia also in T2D patients [34], with a greater relevance among patients treated with MDI compared to basal insulin or non- insulin treatments, and in older population at higher cardiovascular risk [35, 36]. At least one episode of hypoglycemia, mostly asymptomatic, can be revealed in about $49 \%$ of subjects with T2D during a 5-day CGM analysis [37], and the rate of detection appears higher than SMBG alone also in T2D users [38]. Moreover, $36 \%$ of CGM-detected hypoglycemic events were nocturnal. Since the presence of daytime hypoglycemia is the more reliable predictor of nocturnal hypoglycemia, CGM system may be useful in predicting hypoglycemia in high-risk populations such as elderly patients using insulin [38]. CGM can also be helpful in detecting hyperglycemia. A significantly high percentage of time spent above target was also observed by CGM use rather than by SMBG (61\% vs. 51\%), even when insulin doses are stable and well established [39].

Antidiabetic therapies, other than insulin, are usually used to control glucose and diabetes-related diseases [40]. In several trials evaluating the efficacy of combined drug regimens [i.e. sodium-glucose cotransporter 2 (SGLT2) inhibitors or glucagon like peptide 1 receptor agonists (GLP1-ra) with or without insulin] in people with T2D, rtCGM has also been a useful tool to study glucose variability. Among these, in the FLAT-SUGAR study [41], adults with T2D on metformin and basal/bolus insulin therapy were randomized changing to basal insulin plus exenatide (GLP1-ra) or to maintain their therapeutic regimen. In the light of CGM measurements at baseline and at the end of the study, the exenatide group had a significant lowering in glucose variability measured by coefficient of variation (CV), while HbA1c did not change nor were hypoglycemic rates significantly different. Taken together, the studies have shown that CGM is useful in patients with T2D not only as a help to achieve better $\mathrm{HbA1} \mathrm{c}$ values but also to identify unforeseen hypoglycemic risk and address glucose variability [27]. A recent meta-analysis of RCTs by Dicembrini et al. [25], comparing CGM or flash glucose monitoring (FGM) with SMBG in people with T2D on MDI therapy, revealed a marginal difference in HbA1c between CGM and SMBG $(P=0.05)$, with a possible association between CGM use and lower hypoglycemic risk. Recent and emerging evidences suggest that rtCGM can improve glucose control (in term of significantly lower HbA1c and shorter time spent below target) in T2D treatment, however, the impact of the use of these technologies on patients' stress levels and behavior is poorly understood [26]. According to Taylor et al. [42], adults with T2D starting a low-carbohydrate lifestyle plan and wearing an rtCGM or a blinded CGM for 12 weeks, have experienced significant reductions in body weight and HbA1c, with greater acceptance of sensors. Thus, rtCGM may provide an alternative approach to glucose management in individuals with T2D without resulting in increased disease distress. Despite the lack of several trials and evidences about CGM use and its effects on QoL among T2D adults, some available data are able to show a significant high satisfaction with CGM use thanks to different types of Satisfaction Scale Scores [30]. In fact, Beck et al. [30] 
demonstrated high frequency of CGM use in T2D patients on a daily or near-daily basis over 6 months, due to high satisfaction. Moreover, among people with T2D and MDI, glycemic improvements seemed to be achieved with less pharmacological changes in insulin daily doses, compared to T1D patients [30]. In a subset analysis of the full DIAMOND study, glycemic control and patient's satisfaction were ameliorated through the use of CGM also among insulin-treated T1D and T2D subjects over 60 years of age [43]. Another issue is the relevant differences between patients with T1D and T2D about technological skills and diabetes self-management, for example in terms of carbohydrate counting, identifying insulin sensitivity factors, and adopting appropriate corrections. This different attitude can likely limit the ability of T2D people to use CGM and also produce some differences in device satisfaction scores [44]. Among T1D subjects, more likely to be familiar with CGM devices and how to interpret data, the different features and algorithms of the monitoring device could be more relevant in determining satisfaction from their use than patient characteristic. Conversely, for T2D patients a greater device satisfaction using appropriate CGM device is associated with demographic variables (younger age, for example) and a higher willingness or ability to personally take care of their disease [44]. Moreover, the need of glucose devices to support therapeutic decision does not match between T1D and T2D subjects (even if insulin-treated T2D patients). In fact, people with T1D are likely to feel more dependent on glucose technologies than T2D subjects probably because of a greater incidence of severe hypoglycemia and a higher requirement of day-to-day care [44]. CGM device satisfaction and improved QoL among T2D subjects seem to depend on their training and support in self-management and a better use of glucose information.

Today, there are good reasons to believe that CGM would be a useful system for subjects with T2D. In fact, CGM may represent an excellent tool to learn about glycemic variability and self-managing also for patients with T2D, as well as a guide for health care providers to motivate healthy lifestyle and dietary habits. As known, it is important to quickly assess patient's glucose patterns during outpatient clinic visits. In this view, a complete picture of glucose trends and patterns can be provided by the AGP report offered by several systems of glucose monitoring [45]. Using standardized visualizations, clinicians can determine what medication, dosing, timing of meals, or other interventions can be used to improve glucose patterns and increase time in range without increasing hypoglycemia [46].

A systematic review still in press, the PROSPERO study [47], will compare the various forms of CGM systems (i.e. flash CGM, rtCGM, retrospective CGM) versus SMBG among adults with T2D. Primary outcomes will be HbA1c values, body weight, time spent in hypoglycemia and hyperglycemia, blood pressure, and QoL. Secondary outcomes will be user satisfaction and barriers (physical and mental difficulties or issues). The results will support health professionals to determine the most effective methods/technologies particularly in the setting of T2D management.

It is worth mentioning that some limitations in systematic use of CGM technologies among people with T2D could exist and reduce subject's compliance (as shown in Table 3). In particular, the need of daily calibrations through SBGM for some CGM devices could be annoying for users, bringing to incorrect use of the device and consequently to less precise CGM readings. In fact, considering that one of the reasons for adopting CGM devices in T2D people is to manage hypoglycemia and glycemic variability, discrepancies between the values of finger-stick blood glucose and sensor interstitial glucose may occur in case of rapidly glucose fluctuations, and may be a source of frustration for users [48]. A lag time of 5 to 20 minutes is required to equilibrate the vascular and interstitial glucose levels. This can increase the inaccuracy of CGM devices and brought to create the newest CGM systems that require no finger-stick calibration [49]. In addition, alarms for high and low glucose thresholds could be disruptive and could cause the so-called "alarm fatigue". Frustration for sensor's alarms, especially during the night, may lead some patients to interrupt suddenly the use of CGM, and more often to ignore or discontinue CGM-alarms, not allowing to reach their purpose with potentially negative clinical effects [50]. Some authors hypothesize that "alarm fatigue" might be reduced if users have more power to choose and personalize alarms, setting their threshold and intensity based on time of day [50]. Finally, CGM technology produces a big amount of data also available for T2D users, not often experienced to review and interpret all device's information [29]. The support of a qualified and professional team should be evaluated also for T2D subjects regarding diabetes technology use and interpretation. 
Table 2. Effects of CGM/isCGM among people with type 2 diabetes

\begin{tabular}{|c|c|c|c|c|c|c|c|c|}
\hline Reference & $\begin{array}{l}\text { Study } \\
\text { population }\end{array}$ & $\begin{array}{l}\text { Age, } \\
\text { years } \\
\text { (mean } \\
\pm \text { SD) } \\
\end{array}$ & Therapy & $\begin{array}{l}\text { Monitoring } \\
\text { system }\end{array}$ & $\begin{array}{l}\text { Study } \\
\text { design and } \\
\text { follow-up }\end{array}$ & $\begin{array}{l}\text { Primary } \\
\text { endpoint }\end{array}$ & $\begin{array}{l}\text { Primary } \\
\text { results in } \\
\text { CGM/FGM } \\
\text { group }\end{array}$ & $\begin{array}{l}\text { Change in } \\
\text { HbA1c }\end{array}$ \\
\hline \multirow[t]{2}{*}{$\begin{array}{l}\text { Vigersky } \\
\text { RA, } 2012 \\
{[29]}\end{array}$} & \multirow[t]{2}{*}{100} & \multirow[t]{2}{*}{$\begin{array}{l}55.5 \pm \\
9.6\end{array}$} & \multirow{2}{*}{$\begin{array}{l}\text { All } \\
\text { glucose- } \\
\text { lowering } \\
\text { therapies } \\
\text { (except } \\
\text { prandial } \\
\text { insulin) }\end{array}$} & \multirow[t]{2}{*}{$\begin{array}{l}\text { rtCGM vs. } \\
\text { SMBG }\end{array}$} & \multirow[t]{2}{*}{$\begin{array}{l}\text { Prospective/ } \\
\text { two- arms; } \\
52 \text { weeks }\end{array}$} & \multirow[t]{2}{*}{$\mathrm{HbA1c}$} & \multirow[t]{2}{*}{$\begin{array}{l}\text { Reduction of } \\
\text { HbA1c at short } \\
\text { and long-time }\end{array}$} & $\begin{array}{l}-1.0 \% \pm 1.1 \% \\
\text { vs. } 0.5 \% \pm 0.8 \% \\
\text { (at } 12 \text { weeks) }\end{array}$ \\
\hline & & & & & & & & $\begin{array}{l}-0.8 \% \pm 1.5 \% \\
\text { vs. } 0.2 \% \pm 1.3 \% \\
\text { (at } 52 \text { weeks) }\end{array}$ \\
\hline \multirow[t]{3}{*}{$\begin{array}{l}\text { Beck RW, } \\
2017 \text { [30] }\end{array}$} & \multirow[t]{3}{*}{158} & \multirow[t]{3}{*}{$60 \pm 11$} & \multirow[t]{3}{*}{ MDI } & \multirow[t]{3}{*}{$\begin{array}{l}\text { rtCGM vs. } \\
\text { usual care }\end{array}$} & \multirow[t]{3}{*}{$\begin{array}{l}\text { RCT; } 24 \\
\text { weeks }\end{array}$} & \multirow[t]{3}{*}{$\mathrm{HbA1c}$} & \multirow{3}{*}{$\begin{array}{l}\text { - Reduction } \\
\text { in HbA1c } \\
-\quad \text { Increase of } \\
\text { TIR }\end{array}$} & $\begin{array}{l}-1.1 \% \pm 0.7 \% \\
\text { vs. }-0.5 \% \pm\end{array}$ \\
\hline & & & & & & & & $\begin{array}{l}0.7 \% \text { (at } 12 \\
\text { weeks) }\end{array}$ \\
\hline & & & & & & & & $\begin{array}{l}-1.0 \% \pm 0.8 \% \\
\text { vs. }-0.4 \% \pm \\
0.7 \% \text { (at } 24 \\
\text { weeks) }\end{array}$ \\
\hline \multirow[t]{2}{*}{$\begin{array}{l}\text { Allen NA, } \\
2008 \text { [31] }\end{array}$} & \multirow[t]{2}{*}{52} & \multirow[t]{2}{*}{$\begin{array}{l}57 \pm \\
13.5\end{array}$} & \multirow{2}{*}{$\begin{array}{l}\text { All } \\
\text { glucose- } \\
\text { lowering } \\
\text { therapies } \\
\text { (except } \\
\text { insulin) }\end{array}$} & \multirow[t]{2}{*}{$\begin{array}{l}\text { rtCGM } \\
+ \text { phone } \\
\text { counseling }\end{array}$} & \multirow[t]{2}{*}{$\begin{array}{l}\text { Pilot study; } \\
8 \text { weeks }\end{array}$} & \multirow[t]{2}{*}{$\begin{array}{l}\text { Changes in } \\
\text { physical activity } \\
\text { behavior }\end{array}$} & $\begin{array}{l}\text { - Improved } \\
\text { physical } \\
\text { activity }\end{array}$ & $\begin{array}{l}-1.16 \% \pm 1.04 \% \\
\text { vs. }-0.32 \% \pm \\
1.02 \%{ }^{* *}\end{array}$ \\
\hline & & & & & & & $\begin{array}{l}\text { - Reduction } \\
\text { in } \mathrm{HbA} 1 \mathrm{c}\end{array}$ & \\
\hline \multirow{3}{*}{$\begin{array}{l}\text { Zick R, } \\
2007 \\
{[38]}\end{array}$} & \multirow[t]{3}{*}{367} & \multirow[t]{3}{*}{$\begin{array}{l}59.2 \pm \\
8.2\end{array}$} & \multirow[t]{3}{*}{ MDI } & \multirow[t]{3}{*}{$\begin{array}{l}\text { 72h-CGM } \\
\text { vs. SMBG }\end{array}$} & \multirow{3}{*}{$\begin{array}{l}\text { Open-label } \\
\text { RCT; } 8 \\
\text { weeks }\end{array}$} & \multirow[t]{3}{*}{$\begin{array}{l}\text { Detected } \\
\text { hypoglycemia }\end{array}$} & $\begin{array}{l}\text { - Increased } \\
\text { detection of }\end{array}$ & \multirow[t]{3}{*}{$\begin{array}{l}-0.23 \% \pm \\
0.64 \%{ }^{*}\end{array}$} \\
\hline & & & & & & & hypoglycemia & \\
\hline & & & & & & & $\begin{array}{l}\text { - Reduction } \\
\text { in } \mathrm{HbA} 1 \mathrm{c}\end{array}$ & \\
\hline \multirow[t]{2}{*}{$\begin{array}{l}\text { Yaron M, } \\
2018 \text { [54] }\end{array}$} & \multirow[t]{2}{*}{101} & \multirow[t]{2}{*}{$\begin{array}{l}66.7 \pm \\
7.5\end{array}$} & \multirow[t]{2}{*}{ MDI } & $\begin{array}{l}\text { isCGM vs. } \\
\text { SMBG }\end{array}$ & $\begin{array}{l}\mathrm{RCT} ; 12 \\
\text { weeks }\end{array}$ & $\begin{array}{l}\text { - Treatment } \\
\text { satisfaction }\end{array}$ & $\begin{array}{l}\text { - Improved } \\
\text { QoL }\end{array}$ & $\begin{array}{l}-0.82 \% \text { vs. } \\
-0.33 \%\end{array}$ \\
\hline & & & & & & - HbA1c & $\begin{array}{l}\text { - Reduction } \\
\text { in } \mathrm{HbA} 1 \mathrm{c}\end{array}$ & $(\text { control) })^{x}$ \\
\hline $\begin{array}{l}\text { Haak T, } \\
2017\end{array}$ & 224 & $\begin{array}{l}59 \pm \\
9.9\end{array}$ & $\begin{array}{l}\text { MDI or } \\
\text { CSII }\end{array}$ & $\begin{array}{l}\text { isCGM vs. } \\
\text { SMBG }\end{array}$ & $\begin{array}{l}\text { Open-label } \\
\text { RCT; } 6\end{array}$ & $\mathrm{HbA1c}$ & $\begin{array}{l}\text { - Reduction } \\
\text { in } \mathrm{HbA} 1 \mathrm{c}<65\end{array}$ & $\begin{array}{l}-0.53 \% \pm \\
0.09 \% \text { vs. }\end{array}$ \\
\hline [55] & & & & & months & & years & $-0.20 \% \pm 0.12 \%$ \\
\hline & & & & & & & $\begin{array}{l}\text { - Higher } \\
\text { treatment } \\
\text { satisfaction }\end{array}$ & \\
\hline $\begin{array}{l}\text { Midyett K, } \\
2019 \text { [56] }\end{array}$ & 115 & $\begin{array}{l}59 \pm \\
11.5\end{array}$ & $\begin{array}{l}\text { OADs } \\
\text { and MDI }\end{array}$ & $\begin{array}{l}\text { isCGM vs. } \\
\text { SMBG }\end{array}$ & $\begin{array}{l}\text { Pilot study; } \\
2 \text { weeks }\end{array}$ & $\begin{array}{l}\text { Characterization } \\
\text { of glucose } \\
\text { variability }\end{array}$ & $\begin{array}{l}\text { - Agreement } \\
\text { of estimated } \\
\text { HbA1c with } \\
\text { laboratory test }\end{array}$ & NA \\
\hline & & & & & & & $\begin{array}{l}\text { - Applicability } \\
\text { of AGP }\end{array}$ & \\
\hline & & & & & & & $\begin{array}{l}\text { - High } \\
\text { treatment } \\
\text { satisfaction }\end{array}$ & \\
\hline
\end{tabular}

${ }^{*} P<0.01 ;{ }^{* *} P<0.05$. AGP: ambulatory glucose profile; NA: not applicable; TIR: time in range 
Table 3. Pros and cons of CSII and CGM technology among subjects with T2D

\begin{tabular}{|c|c|c|}
\hline & Pros & Cons \\
\hline \multirow{7}{*}{$\begin{array}{l}\text { Both for CSII } \\
\text { and CGM }\end{array}$} & Improvement of $\mathrm{HbA} 1 \mathrm{c}$ level in short and long-term & Only for selected patients suitable for technology \\
\hline & & Necessity of time for specific training \\
\hline & & $\begin{array}{l}\text { Need for healthcare provider team trained to } \\
\text { technology use }\end{array}$ \\
\hline & Usually discrete and easy to wear & Risk of skin reactions at the insertion site \\
\hline & Improved quality of life & \multirow{2}{*}{$\begin{array}{l}\text { Risk of non-adherence or early discontinuation of } \\
\text { technology use }\end{array}$} \\
\hline & $\begin{array}{l}\text { Useful and effective in case of pregnancy and its } \\
\text { planning }\end{array}$ & \\
\hline & & Short term* cost and its coverage \\
\hline \multirow{3}{*}{$\begin{array}{l}\text { CGM specific } \\
\text { issues }\end{array}$} & Reduction of hypoglycemic events & Risk of long term burn-out by alarms \\
\hline & Complete glucose profiles & Big amount of data to be interpreted \\
\hline & No calibration needed for some devices & Calibration needed for some devices \\
\hline \multirow{2}{*}{$\begin{array}{l}\text { CSII specific } \\
\text { issues }\end{array}$} & Tailored insulin therapy & \\
\hline & Efficacy both in obese and in non-obese patients & \\
\hline
\end{tabular}

* long term cost must be evaluated in cost effectiveness studies, to evaluate if long term reduction of diabetes related complications could compensate initial costs

\section{isCGM and T2D}

A few years ago, a new glucose monitoring technology has been developed, the "flash glucose monitoring" (FGM). It is an isCGM designed as an alternative to traditional SMBG, and consists in a sensor providing continuous detection of interstitial glucose data, and obtaining a full glycemic profile of up to 14 days [51]. At any time, the sensor may be wirelessly scanned by the patient with a receiver or with the cellphone application to download the acquired glucose readings, a trend arrow, and the past 8-hour data, without calibration. The clinician can connect glucose reader to a computer-based software or connect to the webbased cloud for the mobile application data storage and can generate summary reports (AGP). This device could give the opportunity to achieve a better glycemic control in subjects with T2D treated with MDI, without increasing the frequency of hypoglycemia. Several studies in subjects with T1D showed that FGM use is associated with an increased time spent in target range of about $44 \%$ and a $38 \%$ reduction in time spent in hypoglycemia [52], with a relation to the number of daily glucose measurements [53]. The side effects reported in some trials [4] were related to the application of the sensor (i.e. allergies, itching, rash or erythema, insertion-site symptoms, oedema). FGM also potentially produces behavioral and/or lifestyle changes and improves treatment satisfaction, since its flexibility and convenience [54]. It is now available, but not yet in all Countries (e.i. Italy), an updated model of FGM device with real-time alarms, therefore potentially useful in the setting of hypoglycemia unawareness.

The first European RCT, the REPLACE study [55], explored the effect of isCGM (FGM) on HbA1c in T2D compared with SMBG. HbA1c decreased significantly in the patients less than 65 years old, indicating that patient selection is fundamental. In addition, FGM was useful for obtaining a significant reduction in nocturnal hypoglycemic events, particularly in people aged above 65 years. The decrease of nocturnal hypoglycemia is likely derived from glucose corrections with pre-bedtime meals or changes in overnight basal insulin dose, on the basis of night-time sensor glucose data. At the same time, reduction of daytime hypoglycemia was possible thanks to on-demand access to sensor glucose data and trend arrows, allowing preventive behavioral actions [54]. Glycemic variability, assessed through mean amplitude of glucose excursions or glucose standard deviation (SD), was not different between the two groups, as well as total, basal or bolus insulin doses. Moreover, safety assessment confirmed that FGM technology is an effective and safe substitute for blood glucose monitoring, provided that the patient is confident in the use of the technology and has a minimum average sensor scanning of eight times per day [55]. In fact, FGM use seems to have a clinical good acceptance by patients with T2D and clinicians [56]. Using AGP derived from FGM downloading to review glycemic profiles and to consider treatment adjustments, is associated with significant reductions in HbA1c 
levels also in T2D subjects due to a rapid and sustained reduction of hyperglycemia [57,58]. Patient treatment satisfaction in the use of FGM was analyzed in the REPLACE study using questionnaire scores that showed significant improvement in satisfaction and QoL $(P<0.0001)$ among insulin-treated T2D people, in term of device comfort, avoidance of blood glucose testing and reduced concerns about hypoglycemia especially for older intervention participants [55]. Together with previously published RCT data (as shown in Table 2), it is now established that FGM technology has a positive impact on glucose control, limits glucose variability, reduces hypoglycemia, and improves long-term glucose control also in people with T2D.

\section{SAP and T2D}

Diabetes technologies were originally developed mainly for T1D, but they can also be useful in insulin-treated T2D, especially for basal-bolus therapy. The discrepancy between people with type 1 and T2D in the use of CSII plus CGM systems may derive from lower glucose variability, more regular lifestyle, and greater difficulty in management of technological devices for people with T2D.

The effectiveness and beneficial effect of SAP therapy in T2D subjects is not well established and more trials comparing SAP to MDI treatment in this setting of disease are necessary. The first multicentre randomized control trial on T2D hospitalized adults [59], comparing SAP and MDI therapy for a 2-week period, showed a significant reduction of the time required to achieve glucose control and metabolic improvement in intervention group $(P<0.001)$, and a decrease of hypoglycemic and hyperglycemic events $(P<0.05)$. The authors also speculated on the idea that reducing time spent with blood glucose $>180 \mathrm{mg} /$ dL during short-term SAP use among hospitalized T2D patients may not only decrease the length of hospital stay but also limit vascular damage and oxidative stress implicated in the etiology of diabetic microvascular complications $[59,60]$.

Today, available data that allow to support clinical and therapeutic decisions and choose what kind of patients are more likely to benefit from CSII, CGM or FGM are still insufficient. In fact, large-scale, pragmatic trials of adequate duration are needed to better define possible recommendations. At the moment, the limited available evidence does not support a widespread use of these combined technologies in T2D, and every single case should be carefully evaluated.

\section{Cost-Effectiveness of Technology in T2D}

The use of CSII in adults with T2D has usually been considered only in the setting of a poor glycemic control despite intensive insulin therapy, oral agents, other injectable therapies, and lifestyle modifications, in patients with good compliance to the correct use of the device [61]. RCTs of T2D patients treated with CSII have shown conflicting results [14], and subsequent meta-analyses have failed to show significant reductions of HbA1c or hypoglycemia [62]. Based on cost and limited evidences, CSII does not represent a routine standard of care for people with T2D who require insulin therapy. Patients on intensive insulin therapy, chosen appropriately, may benefit from CSII, especially if total daily insulin dose is greater than $200 \mathrm{U} /$ day [58]. In one study CSII was described cost-effective compared to MDI, because higher therapeutic costs were compensated by a reduction in diabetic complications [63].

The evidence on CGM effectiveness in patients with T2D is questionable. It has been suggested a shortterm intermittent use of the device in adults with T2D not on prandial insulin, who have HbA1c levels above $7 \%$ and able to use the device $[29,64]$. Until now, not many high-quality data on safety and cost-effectiveness of CGM are available. It is generally accepted that the achievement of a better glycemic control and a reduction of hypoglycemic events represents an appropriate use of technology. However, we still need consistent data from additional well-performed RCTs in patients with different sociodemographic characteristics to confirm that these findings are generalizable to the broader T2D population.

A recent cost-effectiveness analysis on FGM, in patients with T2D using intensive insulin therapy, demonstrated that it was characterized by a lower impact on diabetes-related costs, and considered costeffective compared to current standard of care in the light of its ability to prevent hypoglycemia and improve 
QoL [51]. Possible advantages and disadvantages of using CSI and CGM in people with T2D are shown in Table 3.

It is good to remember that technologies for diabetes care have to adapt to unexpected settings, such as a prolonged lockdown due to Coronavirus (COVID-19) pandemic. An interesting population study recently performed in India included a random list of 3, 000 individuals with T2D [65]. Through a telephonic survey collecting information on changes in lifestyle, access to diabetes care, and use of technologies such as telemedicine. As result, a high level of satisfaction among those who utilized telemedicine was highlighted. The COVID-19 pandemic and the subsequent lockdown seemed to produce an improvement in HbA1c $(\mathrm{P}<$ 0.001 ) in that T2D population. One possible explanation could be that a greater accessibility and acceptance of technology may help individuals with diabetes to maintain strict contact with their health care providers and ensure better metabolic control.

\section{Guidelines}

According to the latest position of Standards of Medical Care in diabetes, the use of diabetes technology in adults with T2D can be regulated in view of its cost-effectiveness [66]. Blinded continuous glucose monitor data, when coupled with diabetes self-management education and medication dose adjustment, can be helpful in identifying and correcting patterns of hyper- and hypo-glycemia in people with T2D. Continuous insulin delivery devices may be appropriate for some patients with T2D who would otherwise require MDI of basal and rapid-acting insulin [66]. Adults with long-standing T2D and likely insulin deficiency, for instance, those who have had a pancreatectomy, or individuals with cystic fibrosis may also benefit from insulin pump therapy. This is considered an individual decision and must be tailored to fit patient needs and preferences.

A current consensus $[46,67]$ is that use of professional CGM (i.e. retrospective-CGM in which the device is a Holter-like system owned by the clinician's practice) should be considered in patients who have not reached their glycemic target after 3 months of the initial anti-hyperglycemic therapy and for those who require therapy that is associated with risks of hypoglycemia (i.e. sulfonylurea, glinide, or insulin). The use of personal CGM devices, on the other hand, should be considered for those patients who are on intensive insulin therapy ( 3 to 4 injections/day or on insulin pump), for those with a history of hypoglycemia unawareness, or those with recurrent hypoglycemia [67]. Digital health services are increasing rapidly worldwide. Today, strategies to involve in self-monitoring on a daily basis and empower T2D persons are very important. Digitalized services have the ability to modify primary health care, providing lifestyle coaching and real-time support and potentially reaching a wide T2D population [68]. However, targeted training to increase digital skills is required and personalized devices must be adapted [69].

The Italian SID-AMD-SIEDP “Technology and Diabetes" Intersociety Group, according to the available evidences [14-16], concluded that in adults with T2D insulin pump therapy may be considered in a setting of poor metabolic control despite optimization of anti-hyperglycemic drugs and MDI intensive therapy. Despite limited evidences and trials about the use of CGM in subjects with T2D, Italian recommendations agree with applying intermittent or CGM in T2D adults at risk of hypoglycemia, as a way to optimize glycemic variability $[24,27,70]$. Retrospective-CGM represents an efficacious method to evaluate glycemic profiles and to make therapeutic changes also in adults with T2D and/or elderly people with severe hypoglycemic episodes. FGM device has been highly recommended both in type 1 and in T2D during intensive insulin treatment (MDI or CSII) to reduce the frequency of hypoglycemic events [71].

\section{Conclusion}

Overall, technologies in diabetes help to reduce glycemic variability, improve the QoL, and decrease HbA1c. These have been commonly developed and used for people with T1D, but in the last years a potential beneficial role has been described also in T2D people. In fact, according to the ADA recommendations, glucose control remains a major issue in the management of patients with T2D, together with a comprehensive cardiovascular risk factor reduction program [33]. In this view, in T2D subjects, who fail to respond to 
non-insulin antihyperglycemic agents, insulin therapy is recommended and often requires intensification of regimens.

Insulin pumps are useful devices for diabetes management, offering insulin dosing flexibility, and reducing hypoglycemia risk. Among these, patch pumps are also emerging as tools for simplified insulin therapy in patients with T2D [72, 73]. Despite limited data from RCTs, longitudinal data suggest that CSII may be preferred to MDI in T2D patients with severe insulin resistance and poor glycemic control despite sufficient insulin titration and adherence to diet and physical exercise [73, 74]. In our opinion, pump therapy may be offered in settings of severe chronic hyperglycemia despite high insulin doses among young and adults with T2D. For young people, CSII system represents an acceptable alternative to MDI as long as they have technological skills and are willing to use a wearable device. Patch pumps may improve compliance and QoL among elderly people with T2D in stable dosage of MDI therapy, who cannot self-administer insulins by pens. Patients with T2D can be often obese, exhibiting high abdominal fat content despite adequate nutrition. Applying CSII therapy may be hypothesized in order to reduce post-meal excursions through correction boluses. Other possible indications of CSII use in people with T2D may include lipodystrophy syndromes, pregnancy, and cutaneous insulin allergy. Few contraindications should be ruled out such as active proliferative retinopathy, psychiatric disorders, lack of motivation for using pump, or mental or physical disability. A situation in which changing to CSII treatment can be more beneficial and effective than MDI is that of patients who underwent pancreatectomy for any cause, who developed unstable iatrogenic diabetes characterized by early post-prandial hyperglycemia followed by episodes of severe hypoglycemia. Moreover, in pancreatogenic diabetes, the predictive low-glucose suspend algorithm within sensor-augmented CSII system can represent an excellent option for managing diabetes.

CGM provides to people with T2D additional information about glycemic control beyond HbA1c, but its usefulness has been less clear in this population. Guidelines from the ADA and the American Association of Clinical Endocrinologists generally endorse the use of CGM for people at risk for hypoglycemia, especially unawareness, regardless of diabetes type [46]. rtCGM and isCGM devices in T2D have shown promising results in improving glycemic control, reducing the risk of hypoglycemia, and increasing the time spent in the target range. They can be useful in subjects with T2D at risk for insulin-induced hypoglycemia by activation of alarms. Retrospective CGM in specialized endocrinology setting, or eventually in primary care, is a great tool to review glucose patterns and share decisions with the patient, even if not widely utilized yet. CGM is also effective among patients with severe chronic kidney disease, T2D, and hemodialysis, in which HbA1c has less accuracy as a marker of glycemic control.

Instead of a one-size-fits-all approach, a tailored approach is necessary in the management of T2D, balancing the benefits of a better glycemic control derived from the use of technology with the potential misuse of these devices in the absence of a multidisciplinary and experienced diabetes team.

\section{Abbreviations}

ADA: American Diabetes Association

AGP: ambulatory glucose profile

BG: blood glucose

CGM: continuous glucose monitoring

CSII: continuous subcutaneous insulin infusion

FGM: flash glucose monitoring

HbA1c: glycated hemoglobin

isCGM: intermittently scanned continuous glucose monitoring

MDI: multiple daily injection

OADs: oral antidiabetic drugs

QoL: quality of life 
RCT: randomized controlled trial

rtCGM: real-time continuous glucose monitoring

SAP: sensor augmented pump

SD: standard deviation

SMBG: self-monitoring blood glucose

T1D: type 1 diabetes

T2D: type 2 diabetes

\section{Declarations}

\section{Author contributions}

AMB and AL conceived the idea of the manuscript and designed the project; AA, AC, AMB and EP organized the collected data to review; EP wrote the first draft of the manuscript with the supervision of $A M B, A C$ and AL; AC, AMB and AL contributed to work design and critically reviewed the manuscript. All authors discussed the project, contributed to manuscript revision, read and approved the submitted version.

\section{Conflicts of interest}

The authors declare that they have no conflicts of interest.

Ethical approval

Not applicable.

\section{Consent to participate}

Not applicable.

\section{Consent to publication}

Not applicable.

\section{Availability of data and materials}

Not applicable.

\section{Funding}

Not applicable.

\section{Copyright}

(C) The Author(s) 2020 .

\section{References}

1. Raskin P, Bode BW, Marks JB, Hirsch IB, Weinstein RL, McGill JB, et al. Continuous subcutaneous insulin infusion and multiple daily injection therapy are equally effective in type 2 diabetes: a randomized, parallel-group, 24-week study. Diabetes Care. 2003;26:2598-603.

2. Bosi E, Scavini M, Ceriello A, Cucinotta D, Tiengo A, Marino R, et al. Intensive structured self-monitoring of blood glucose and glycemic control in noninsulin-treated type 2 diabetes: the PRISMA randomized trial. Diabetes Care. 2013;36:2887-94.

3. Rodbard D. Continuous glucose monitoring: a review of recent studies demonstrating improved glycemic outcomes. Diabetes Technol Ther. 2017;19 Suppl 3:S25-37.

4. Bolinder J, Antuna R, Geelhoed-Duijvestijn P, Kröger J, Weitgasser R. Novel glucose-sensing technology and hypoglycemia in type 1 diabetes: a multicentre, non-masked, randomised controlled trial. Lancet. 2016;388:2254-63. 
5. Nathan DM, Buse JB, Davidson MB, Ferrannini E, Holman RR, Sherwin R, et al; American Diabetes Association; European Association for Study of Diabetes. Medical management of hyperglycemia in type 2 diabetes: a consensus algorithm for the initiation and adjustment of therapy: a consensus statement of the American Diabetes Association and the European Association for the Study of Diabetes. Diabetes Care. 2009;32:193-203.

6. Miller CD, Phillips LS, Ziemer DC, Gallina DL, Cook CB, El-Kebbi IM. Hypoglycemia in patients with type 2 diabetes mellitus. Arch Intern Med. 2001;161:1653-9.

7. Holman RR, Farmer AJ, Davies MJ, Levy JC, Darbyshire JL, Keenan JF, et al; 4-T Study Group. Three-year efficacy of complex insulin regimens in type 2 diabetes. N Engl J Med. 2009;361:1736-47.

8. Misso ML, Egberts KJ, Page M, O'Connor D, Shaw J. Continuous subcutaneous insulin infusion (CSII) versus multiple insulin injections for type 1 diabetes mellitus. Cochrane Database Syst Rev. 2010:CD005103.

9. Scott ES, McGrath RT, Januszewski AS, Calandro D, Hardikar AA, O'Neal DN, et al. HbA1c variability in adults with type 1 diabetes on continuous subcutaneous insulin infusion (CSII) therapy compared to multiple daily injection (MDI) treatment. BMJ Open. 2019;9:e033059.

10. Pickup JC, Sutton AJ. Severe hypoglycaemia and glycaemic control in Type 1 diabetes: meta-analysis of multiple daily insulin injections compared with continuous subcutaneous insulin infusion. Diabet Med. 2008;25:765-74.

11. Pickup J, Mattock M, Kerry S. Glycaemic control with continuous subcutaneous insulin infusion compared with intensive insulin injections in patients with type 1 diabetes: meta-analysis of randomised controlled trials. BMJ. 2002;324:705.

12. EQuality1 Study Group--Evaluation of QUALITY of Life and Costs in Diabetes Type 1; Nicolucci A, Maione A, Franciosi M, Amoretti R, Busetto E, Capani F, et al. Quality of life and treatment satisfaction in adults with Type 1 diabetes: a comparison between continuous subcutaneous insulin infusion and multiple daily injections. Diabet Med. 2008;25:213-20.

13. Bode BW. Insulin pump use in type 2 diabetes. Diabetes Technol Ther. 2010;12 Suppl 1:S17-21.

14. Reznik Y, Cohen O, Aronson R, Conget I, Runzis S, Javier Castaneda, et al; OpT2mise Study Group. Insulin pump treatment compared with multiple daily injections for treatment of type 2 diabetes (OpT2mise): a randomised open-label controlled trial. Lancet. 2014;384:1265-72.

15. Aronson R, Reznik Y, Conget I, Castañeda JA, Runzis S, Lee SW, et al; OpT2mise Study Group. Sustained efficacy of insulin pump therapy compared with multiple daily injections in type 2 diabetes: 12-month data from the OpT2mise randomized trial. Diabetes Obes Metab. 2016;18:500-7.

16. Pickup JC, Reznik Y, Sutton AJ. Glycemic control during continuous subcutaneous insulin infusion versus multiple daily insulin injections in type 2 diabetes: individual patient data meta-analysis and metaregression of randomized controlled trials. Diabetes Care. 2017;40:715-22.

17. Milluzzo A, Vigneri P, Martorana F, Vigneri R, Sciacca L. Type 2 diabetes and cancer: problems and suggestions for best patient management. Explor Med. 2020;1:184-204.

18. Berthe E, Lireux B, Coffin C, Goulet-Salmon B, Houlbert D. Boutreux S, et al. Effectiveness of intensive insulin therapy by multiple daily injections and continuous subcutaneous infusion: a comparison study in type 2 diabetes with conventional insulin regimen failure. Horm Metab Res. 2007;39:224-9.

19. American Diabetes Association. Standards of medical care in diabetes--2009. Diabetes Care. 2009;32 Suppl 1:S13-61.

20. National coverage analysis (NCA) tracking sheet for insulin pump: C-peptide levels as a criterion for use (CAG-00092R) [Internet]. Maryland: the U.S. Centers for Medicare \& Medicaid Services; 2004 [cited 2020 Sep 14]. Available from: https://www.cms.gov/medicare-coverage-database/details/ncatracking-sheet.aspx?NCAId=109\&from db=true

21. Ginsberg BH. Patch pumps for insulin. J Diabetes Sci Technol. 2019;13:27-33. 
22. Lajara R, Davidson JA, Nikkel CC, Morris TL. Clinical and cost-effectiveness of insulin delivery with V-GO (®) disposable insulin delivery device versus multiple daily injections in patients with type 2 diabetes inadequately controlled on basal insulin. Endocr Pract. 2016;22:726-35.

23. Wahlqvist P, Warner J, Morlock R. Cost-effectiveness of simple insulin infusion devices compared to multiple daily injections in uncontrolled type 2 diabetics in the United States based on a simulation model. J Health Econ Outcomes Res. 2018;6:84-95.

24. Vigersky RA, Huang S, Cordero TL, Shin J, Lee SW, Chhabra H, et al; OpT2mise Study Group. Improved HbA1c, total daily insulin dose, and treatment satisfaction with insulin pump therapy compared to multiple daily insulin injections in patients with type 2 diabetes irrespective of baseline C- peptide levels. Endocr Pract. 2018;24:446-52.

25. Dicembrini I, Mannucci E, Monami M, Pala L. Impact of technology on glycemic control in type 2 diabetes: a meta-analysis of randomized trials on continuous glucose monitoring and continuous subcutaneous insulin infusion. Diabetes Obes Metab. 2019;21:2619-25.

26. Ida S, Kaneko R, Murata K. Utility of real-time and retrospective continuous glucose monitoring in patients with type 2 diabetes mellitus: a meta-analysis of randomized controlled trials. J Diabetes Res. 2019;2019:4684815.

27. Beck RW, Riddlesworth T, Ruedy K, Ahmann A, Bergenstal R, Haller S, et al; DIAMOND Study Group. Effect of continuous glucose monitoring on glycemic control in adults with type 1 diabetes using insulin injections: the DIAMOND randomized clinical trial. JAMA. 2017;317:371-8.

28. Carlson AL, Mullen DM, Bergenstal RM. Clinical use of continuous glucose monitoring in adults with type 2 diabetes. Diabetes Technol Ther. 2017;19:S4-11.

29. Vigersky RA, Fonda SJ, Chelleppa M, Walker MS, Ehrhardt NM. Short- and long-term effects of real-time continuous glucose monitoring in patients with type 2 diabetes. Diabetes Care. 2012;35:32-8.

30. Beck RW, Riddlesworth TD, Ruedy K, Ahmann A, Haller S, Kruger D, et al; DIAMOND Study Group. Continuous glucose monitoring versus usual care in patients with type 2 diabetes receiving multiple daily insulin injections: a randomized trial. Ann Intern Med. 2017;167:365-74.

31. Allen NA, Fain JA, Braun B, Chipkin SR. Continuous glucose monitoring counseling improves physical activity behaviors of individuals with type 2 diabetes: a randomized clinical trial. Diabetes Res Clin Pract. 2008;80:371-9.

32. Fonda SJ, Graham C, Munakata J, Powers JM, Price D, Vigersky RA. The cost-effectiveness of real-time continuous glucose monitoring (RT-CGM) in type 2 diabetes. J Diabetes Sci Technol. 2016;10:898-904.

33. American Diabetes Association. 7. Diabetes technology: standards of medical care in diabetes--2020. Diabetes Care. 2020;43:S77-88.

34. New JP, Ajjan R, Pfeiffer AFH, Freckmann G. Continuous glucose monitoring in people with diabetes: the randomized controlled Glucose Level Awareness in Diabetes Study (GLADIS). Diabet Med. 2015;32:609-17.

35. Wright AD, Cull CA, Macleod KM, Holman RR; UKPDS Group. Hypoglycemia in Type 2 diabetic patients randomized to and maintained on monotherapy with diet, sulfonylurea, metformin, or insulin for 6 years from diagnosis: UKPDS73. J Diabetes Complications. 2006;20:395-401.

36. Zoungas S, Patel A, Chalmers J, de Galan BE, Li Q, Billot L, et al; ADVANCE Collaborative Group. Severe hypoglycemia and risks of vascular events and death. N Engl J Med. 2010;363:1410-8.

37. Gehlaut RR, Dogbey GY, Schwartz FL, Marling CR, Shubrook JH. Hypoglycemia in type 2 diabetes--more common than you think: a continuous glucose monitoring study.J Diabetes Sci Technol. 2015;9:999-1005.

38. Zick R, Petersen B, Richter M, Haug C; SAFIR Study Group. Comparison of continuous blood glucose measurement with conventional documentation of hypoglycemia in patients with Type 2 diabetes on multiple daily insulin injection therapy. Diabetes Technol Ther. 2007;9:483-92. 
39. Pazos-Couselo M, García-López JM, González-Rodríguez M, Gude F, Mayán-Santos JM, Rodríguez-Segade $\mathrm{S}$, et al. High incidence of hypoglycemia in stable insulin-treated type 2 diabetes mellitus: continuous glucose monitoring vs. self-monitored blood glucose. Observational prospective study. Can J Diabetes. 2015;39:428-33.

40. Mantovani A, Beatrice G, Petracca G, Pampagnin F, Sandri D, Targher G. GLP-1 receptor agonists for NAFLD treatment in patients with and without type 2 diabetes: an updated meta-analysis. Explor Med. 2020;1:108-23.

41. FLAT-SUGAR trial investigators. Glucose variability in a 26-week randomized comparison of mealtime treatment with rapid-acting insulin versus GLP1 agonist in participants with type 2 diabetes at high cardiovascular risk. Diabetes Care. 2016;39:973-81.

42. Taylor PJ, Thompson CH, Luscombe-Marsh ND, Wycherley TP, Wittert G, Brinkworth GD, et al. Tolerability and acceptability of real-time continuous glucose monitoring and its impact on diabetes management behaviors in individuals with Type 2 Diabetes - a pilot Study. Diabetes Res Clin Pract. 2019;155:107814.

43. Ruedy KJ, Parkin CG, Riddlesworth TD, Graham C; DIAMOND Study Group. Continuous glucose monitoring in older adults with type 1 and type 2 diabetes using multiple daily injections of insulin: results from the DIAMOND trial. J Diabetes Sci Technol. 2017;11:1138-46.

44. Polonsky WH, Fisher L, Hessler D, Edelman SV. Development of a new measure for assessing glucose monitoring device-related treatment satisfaction and quality of life. Diabetes Technol Ther. 2015;17:657-63.

45. Bergenstal RM, Ahmann AJ, Bailey T, Beck RW, Bissen J, Buckingham B, et al. Recommendations for standardizing glucose reporting and analysis to optimize clinical decision making in diabetes: the ambulatory glucose profile (AGP). Diabetes Technol Ther. 2013;15:198-211.

46. Bailey TS, Grunberger G, Bode BW, Handelsman Y, Hirsch IB, Jovanovič L, et al; American Association of Clinical Endocrinologists (AACE); American College of Endocrinology (ACE). American Association of Clinical Endocrinologists and American College of Endocrinology 2016 outpatient glucose monitoring consensus statement. Endocr Pract. 2016;22:231-61.

47. Zheng M, Luo Y, Lin W, Khoja A, He Q, Yang S, et al. Comparing effects of continuous glucose monitoring systems (CGMs) and self-monitoring of blood glucose (SMBG) amongst adults with type 2 diabetes mellitus: a systematic review protocol. Syst Rev. 2020;9:120.

48. Klonoff DC, Buckingham B, Christiansen JS, Montori VM, Tamborlane WV, Vigersky RA, et al. Continuous glucose monitoring: an Endocrine Society Clinical Practice Guideline. J Clin Endocrinol Metab. 2011;96:2968-79.

49. Janapala RN, Jayaraj JS, Fathima N, Kashif T, Usman N, Dasari A, et al. Continuous glucose monitoring versus self-monitoring of blood glucose in type 2 diabetes mellitus: a systematic review with metaanalysis. Cureus. 2019;11:e5634.

50. Shivers JP, Mackowiak L, Anhalt H, Zisser H. "Turn it off!": diabetes device alarm fatigue considerations for the present and the future. J Diabetes Sci Technol. 2013;7:789-94.

51. Bilir SP, Hellmund R, Wehler E, Li H, Munakata J, Lamotte M. The cost-effectiveness of a flash glucose monitoring system for management of patients with type 2 diabetes receiving intensive insulin treatment in Sweden. Eur endocrinol. 2018;14:80-5.

52. Dunn TC, Xu Y, Hayter G, Ajjan RA. Real-world flash glucose monitoring patterns and associations between self-monitoring frequency and glycaemic measures: a European analysis of over 60 million glucose tests. Diabetes Res Clin Pract. 2018;137:37-46.

53. Laurenzi A, Caretto A, Barrasso M, Bolla AM, Dozio N, Molinari C, et al. Frequency of flash glucose monitoring readings, hemoglobin $\mathrm{A} 1 \mathrm{C}$ and time in range: a real life study in adults with type 1 diabetes. Acta Diabetol. 2020;57:1395-7. 
54. Yaron M, Roitman E, Aharon-Hananel G, Landau Z, Ganz T, Karp M, et al. Intervention of the flash glucose sensing technology on glycemic control and treatment satisfaction in patients with type 2 diabetes treated intensively using insulin--a randomized controlled trial. Diabetes. 2018;67:908-P.

55. Haak T, Hanaire H, Ajjan R, Hermanns N, Riveline JP, Rayman G, et al. Flash glucose-sensing technology as a replacement for blood glucose monitoring for the management of insulin-treated type 2 diabetes: a multicenter, open-label randomized controlled trial. Diabetes Ther. 2017;8:55-73.

56. Midyett K, Unger JR, Wright EE, Daniel TD, Kruger DF, Henry RR, et al. A pilot study to assess clinical utility and user experience of professional continuous glucose monitoring among people with type 2 diabetes. Clin Diabetes. 2019;37:57-64.

57. Anjana RM, Kesavadev J, Neeta D, Tiwaskar M, Pradeepa R, Jebarani S, et al. A multicenter real-life study on the effect of flash glucose monitoring on glycemic control in patients with type 1 and type 2 diabetes. Diabetes Technol Ther. 2017;19:533-40.

58. Evans M, Welsh Z, Ells S, Seibold A. The impact of flash glucose monitoring on glycemic control as measured by HbA1c: a meta-analysis of clinical trials and real-world observational studies. Diabetes Ther. 2020;11:83-95.

59. Gu W, Liu Y, Chen Y, Deng W, Ran X, Chen L, et al. Multicentre randomized controlled trial with sensoraugmented pump vs multiple daily injections in hospitalized patients with type 2 diabetes in China: time to reach target glucose. Diabetes Metab. 2017;43:359-63.

60. Su G, Mi S, Tao H, Li Z, Yang H, Zheng H, et al. Association of glycemic variability and the presence and severity of coronary artery disease in patients with type 2 diabetes. Cardiovasc Diabetol. 2011;10:19.

61. Peters AL, Ahmann AJ, Battelino T, Evert A, Hirsch IB, Murad MH, et al. Diabetes technology-continuous subcutaneous insulin infusion therapy and continuous glucose monitoring in adults: an endocrine society clinical practice guideline. J Clin Endocrinol Metab. 2016;101:3922-37.

62. Yeh HC, Brown TT, Maruthur N, Ranasinghe P, Berger Z, Suh YD, et al. Comparative effectiveness and safety of methods of insulin delivery and glucose monitoring for diabetes mellitus: a systematic review and meta-analysis. Ann Intern Med. 2012;157:336-47.

63. Roze S, Duteil E, Smith-Palmer J, de Portu S, Valentine W, de Brouwer BF, et al. Cost-effectiveness of continuous subcutaneous insulin infusion in people with type 2 diabetes in the Netherlands. J Med Econ. 2016;19:742-9.

64. Park C, Le QA. The effectiveness of continuous glucose monitoring in patients with type 2 diabetes: a systematic review of literature and meta-analysis. Diabetes Technol Ther. 2018;20:613-21.

65. Anjana RM, Pradeepa R, Deepa M, Jebarani S, Venkatesan U, Parvathi SJ, et al. Acceptability and utilization of newer technologies and effects on glycemic control in type 2 diabetes: lessons learned from lockdown. Diabetes Technol Ther. 2020;22:527-34.

66. Inzucchi SE, Bergenstal RM, Buse JB, Diamant M, Ferrannini E, Nauck M, et al. Management of hyperglycemia in type 2 diabetes, 2015: a patient-centered approach: update to a position statement of the American Diabetes Association and the European Association for the Study of Diabetes. Diabetes Care. 2015;38:140-9.

67. Grunberger G, Bailey T, Camacho PM, Einhorn D, Garber AJ, Handelsman Y, et al. Proceedings from the American Association of Clinical Endocrinologists and American College of Endocrinology consensus conference on glucose monitoring. Endocr Pract. 2015;21:522-33.

68. Bollyky JB, Bravata D, Yang J, Williamson M, Schneider J. Remote lifestyle coaching plus a connected glucose meter with certified diabetes educator support improves glucose and weight loss for people with type 2 diabetes. J Diabetes Res. 2018;2018:3961730.

69. Öberg U, Isaksson U, Jutterström L, Orre CJ, Hörnsten Å. Perceptions of persons with type 2 diabetes treated in Swedish primary health care: qualitative study on using eHealth services for self-management support. JMIR Diabetes. 2018;3:e7. 
70. Ehrhardt NM, Chellappa M, Walker MS, Fonda SJ, Vigersky RA. The effect of real-time continuous glucose monitoring on glycemic control in patients with type 2 diabetes mellitus. J Diabetes Sci Technol. 2011;5:668-75.

71. Reddy M, Jugnee N, El Laboudi A, Spanudakis E, Anantharaja S, Oliver N. A randomized controlled pilot study of continuous glucose monitoring and flash glucose monitoring in people with Type 1 diabetes and impaired awareness of hypoglycaemia. Diabet Med. 2018;35:483-90.

72. Reznik Y, Cohen O. Insulin pump for type 2 diabetes: use and misuse of continuous subcutaneous insulin infusion in type 2 diabetes. Diabetes Care. 2013;36 suppl 2:S219-25.

73. Reznik Y, Morera J, Rod A, Coffin C, Rousseau E, Lireux B, et al. Efficacy of continuous subcutaneous insulin infusion in type 2 diabetes mellitus: a survey on a cohort of 102 patients with prolonged followup. Diabetes Technol Ther. 2010;12:931-6.

74. Kravarusic J, Aleppo G. Diabetes technology use in adults with type 1 and type 2 diabetes. Endocrinol Metab Clin North Am. 2020;49:37-55. 